\title{
Implicações da radioterapia no tratamento do glioma de baixo grau na odontologia: relato de caso
}

\section{Implications of radiotherapy in the treatment of low-grade glioma in dentistry: a case report}

DOI: $10.46919 / \operatorname{archv2n1-011~}$

Recebimento dos originais: 30/10/2020

Aceitação para publicação: 23/12/2020

\author{
Bianca Puppin Gummella \\ Cirurgiã dentista pela Universidade Tuiuti do Paraná \\ Instituição: Universidade Tuiuti do Paraná \\ Endereço: Rua Sydnei Antônio Rangel Santos 238, Santo Inácio, Curitiba-PR, Brasil \\ E-mail: biapuppin@ hotmail.com \\ Ana Claudia Galvão de Aguiar Koubik \\ Mestre em Estomatologia pela Universidade Católica do Paraná \\ Instituição: Universidade Tuiuti do Paraná \\ Endereço: Rua Sydnei Antônio Rangel Santos 238, Santo Inácio, Curitiba-PR, Brasil \\ E-mail: anakoubik@gmail.com \\ Daniel More Zunsztern \\ Cirurgião dentista pela Universidade Tuiuti do Paraná \\ Instituição: Universidade Tuiuti do Paraná \\ Endereço: Rua Sydnei Antônio Rangel Santos 238, Santo Inácio, Curitiba-PR, Brasil \\ E-mail: danielmozu@hotmail.com \\ Mariana de Aguiar Koubik \\ Médica pela Faculdade Evangélica Mackenzie do Paraná / Residente em Ginecologia e Obstetrícia pelo \\ Complexo Hospitalar do Trabalhador \\ Instituição: Complexo Hospitalar do Trabalhador - Universidade Federal do Paraná \\ Endereço: Avenida República Argentina, 4406 - Novo Mundo, Curitiba - PR, Brasil \\ E-mail: marianakoubik@gmail.com
}

\section{RESUMO}

Gliomas de baixo grau são tumores cerebrais que afetam predominantemente adultos jovens com potencial de comprometimento da capacidade cognitiva, podendo levar a óbito. $O$ tratamento baseia-se principalmente na excisão cirúrgica, radioterapia e/ou quimioterapia. Objetivos: identificar e descrever as implicações do tratamento do glioma de baixo grau na odontologia e os prejuízos da radioterapia, por meio de uma revisão de literatura e relato de caso. Metodologia: buscas em bases de dados internacionais PubMed/MEDLINE e Scielo. O presente relato descreve paciente do sexo masculino, acometido por glioma de baixo grau. Resultados e Conclusões: o paciente relatado sofreu dermatite da pele irradiada pelas sessões de radioterapia, uma leve perda de cabelos e alguns episódios de cefaléia. Contudo não teve nenhum problema bucal consequente da radioterapia como xerostomia, disfagia, candidíase, alteração no paladar, trismo, cárie de radiação, doença periodontal e osteorradionercrose. O acompanhamento odontológico aos pacientes antes, durante e após o tratamento é fundamental para melhorar a sua qualidade de vida. 
Palavras-chave: Glioma de baixo grau, tumor cerebral e radioterapia.

\begin{abstract}
Low-grade gliomas are brain tumors that predominantly affect young adults with the potential of impairing cognitive ability and sometimes leading to death. Treatment is mainly based on surgical excision, radiotherapy and/or chemotherapy. Objectives: To identify and describe the implications of the treatment of low grade glioma in dentistry and the damage caused by radiotherapy, through a literature review and case report. Methodology: searches in international PubMed / MEDLINE and Scielo databases. This report describes a male patient with low-grade glioma. Results and Conclusions: The reported patient suffered skin dermatitis caused by radiotherapy sessions, mild hair loss and some episodes of headache. However, there were no oral problems resulting from radiotherapy such as xerostomia, dysphagia, candidiasis, taste alteration, trismus, radiation caries, periodontal disease and osteoradionecrosis. Dental follow-up to patients before, during and after treatment is essential to improve their quality of life.
\end{abstract}

Key words: Low grade glioma, brain tumor and radiotherapy.

\title{
1 INTRODUÇÃO
}

O Sistema Nervoso Central (SNC) é o local de diversas doenças incapacitantes, como as doenças neurodegenerativas, tumores e desordens neurológicas. ${ }^{1}$ Os gliomas correspondem $27 \%$ de todos os tumores do SNC e somam cerca de $80 \%$ dos tumores malignos cerebrais. ${ }^{2}$

Gliomas de baixo grau são tumores cerebrais que afetam predominantemente adultos jovens com potencial de comprometimento da capacidade cognitiva, podendo levar ao óbito. Apresenta crescimento lento com prognóstico mais favorável em comparação aos gliomas de alto grau, correspondendo de 10 a $20 \%$ dos tumores primários do SNC em adultos. ${ }^{3}$

Os pacientes com glioma de baixo grau apresentam uma redução significativa em algumas funções cognitivas, como a velocidade de processamento das informações, funções psicomotoras, de atenção, memória verbal e trabalho e nas funções executivas que são os processos complexos que permitem ao indivíduo desempenhar ações voluntárias, independentes, autônomas, auto-organizadas e orientadas para uma meta específica. Os tumores cerebrais afetam cada paciente de forma diferente a depender do tipo histológico e localização anatômica. No entanto, a maioria apresenta deterioração cognitiva, sintomas físicos e disfunção emocional que invariavelmente interferem nas suas atividades diárias. ${ }^{4}$

O tratamento cirúrgico dos gliomas de baixo grau é possível pela possibilidade de ressecção completa. Enquanto os gliomas de mais alto grau, como o glioblastoma multiforme, com alta capacidade infiltrativa, necessitam de terapêuticas adicionais, sendo praticamente impossível a remoção cirúrgica total. O procedimento cirúrgico pode associar-se à radioterapia e quimioterapia adjuvantes. ${ }^{5}$

\section{REVISÃO DE LITERATURA}

O Sistema Nervoso Central (SNC) apresenta uma imensa diversidade celular, além de estar associado a atividades que envolvem a relação do indivíduo com o meio ambiente, o emocional e a atividade 
intelectual do homem. Aliado à sua complexidade morfológica e funcional, o SNC é local de diversas doenças incapacitantes, como as doenças neurodegenerativas, tumores e desordens neurológicas. Essas doenças, além de afetarem diretamente a qualidade de vida, demandam altos custos financeiros para a saúde pública do país. Os avanços acerca do conhecimento sobre os astrócitos, o mais abundante tipo glial, e o entendimento do funcionamento cerebral apresentam evidências da relação entre disfunções gliais e doenças neurodegenerativas e desordens neurológicas, discutindo o potencial papel dessas células na elaboração de abordagens terapêuticas para o sistema nervoso adulto. As células gliais, constituintes do tecido nervoso juntamente com os neurônios, foram consideradas até pouco tempo células de suporte do cérebro, passivas e à margem do seu funcionamento. Especialmente na última década, as neurociências foram palco de uma mudança de paradigma relacionada à função e ao papel dessas células na fisiologia e patologia neurais. ${ }^{1}$

De acordo com o Instituto Nacional de Câncer, a incidência estimada de neoplasia do SNC é de 5,50 casos novos a cada 100 mil homens e 4,68 para cada 100 mil mulheres no Brasil em 2016. ${ }^{6}$

Dolecek et al. ${ }^{2}$ (2012) com o objetivo de fornecer uma revisão atual e abrangente da epidemiologia descritiva dos tumores cerebrais primários e do sistema nervoso central (SNC) da população dos Estados Unidos, criaram o Relatório Estatístico CBTRUS: Tumores Cerebrais Primários e do Sistema Nervoso Central Diagnosticados nos Estados Unidos em 2005-2009. O CBTRUS é uma organização de pesquisa profissional que se concentra exclusivamente no fornecimento de dados estatísticos de qualidade sobre tumores cerebrais primários baseados em populações e do SNC nos Estados Unidos. Eles relatram que os gliomas correspondem $27 \%$ de todos os tumores do SNC e somam cerca de $80 \%$ dos tumores malignos cerebrais.

Os gliomas são tumores que se iniciam em células da glia, uma substância não-neuronal composta por células que formam a mielina e providenciam suporte, proteção e mantêm a homeostasia das células neuronais. Entre estas células estão os astrócitos, os oligodendrócitos, as células ependimárias e a microglia. $^{7}$

A microglia tem como principal função a defesa imune do SNC, sendo, em geral, recrutada após infecções, lesões ou doenças degenerativas do Sistema Nervoso. A macroglia compreende em oligodendroglia, responsável pela mielinização dos axônios e composta pelos oligodendrócitos; a ependimoglia que compreende os ependimócitos, células que revestem os ventrículos encefálicos e o canal central da medula, as células epiteliais pigmentares da retina e as células do plexo corioideo, presentes no interior dos ventrículos e que produzem o líquido cefalorraquidiano, o líquor; a astroglia que inclui astrócitos, principal fonte de fatores de crescimento para os neurônios e presentes em diversas regiões do SNC; além de alguns tipos especializados de astroglia como, glia de Bergmann no cerebelo, glia de Müller na retina, tanicitos no hipotálamo, os pituicitos na neuro-hipófise e células de glia radial responsáveis por 
guiar a migração neuronal durante o desenvolvimento das estruturas em camadas do sistema nervoso como córtex cerebral, cerebelo e medula espinhal, atualmente têm sido foco de grandes estudos, uma vez que, além de gerarem astrócitos, são consideradas as principais células-tronco do córtex cerebral, gerando, também, neurônios. Ransom e Kettenmann (1990) descreveram as evidências do acoplamento elétrico e corante entre oligodendrócitos e astrócitos em culturas de medula espinhal de camundongos. Na maioria dos experimentos, a corrente foi injetada em oligodendrócitos durante a gravação de voltagem em astrócitos próximos. Nove dos 17 pares de células de oligodendrócito-córtex apresentaram fraco acoplamento elétrico. Esses achados documentaram a presença de fraco acoplamento elétrico entre astrócitos e oligodendrócitos, na ausência de acoplamento de corante. ${ }^{8}$

De acordo com Wang e $\mathrm{Li}^{9}$ (2018), o glioma é um tumor comum do SNC que representa 30\% das incidências de tumores intracranianos. Dados pré-clínicos e clínicos indicam que as terapias antiangiogênicas são potenciais em glioblastoma e pode transitoriamente normalizar vasos tumorais. Isso cria uma janela de oportunidade para otimizar a combinação de quimioterápicos e radiação. Gliomas são neoplasias de natureza altamente infiltrativas. Os estágios diferentes dos gliomas caracterizam suas mudanças genéticas, de genomas e epigenéticas distintas.

Conforme a Organização Mundial de Saúde (OMS), os gliomas são classificados em 4 graus histológicos conforme o grau de diferenciação, anaplasia e de agressividade. Divide-se em: Grau I, II e III e IV. Os gliomas com graduação I e II incluem astrocitomas pilocítico e astrocitomas difuso. Apresentam celularidade aumentada e atípica, porém sem mitoses, proliferação endotelial ou necrose. Os astrocitomas anaplásicos, de grau III, apresentam mitoses, porém sem proliferação endotelial ou necrose. Os glioblastomas são astrocitomas grau IV com alta atividade mitótica, proliferação endotelial e necrose. O estudo de Cohen, Holmen e Colman (2013) apresentou como objetivo identificar as principais alterações genéticas e epigenéticas e definir importantes subtipos moleculares em glioblastomas e gliomas de baixo grau. Embora várias alterações genéticas importantes nos gliomas sejam conhecidas há algum tempo, as novas tecnologias permitiram análises genéticas e epigenéticas muito mais profundas de um número maior de amostras de glioma, levando a uma série de novas descobertas nos últimos anos. Os gliomas com gene IDH1 e gene IDH2 mutados melhoraram o prognóstico em comparação com os gliomas com gene IDH de tipo selvagem. O gene IDH mutado pode agora ser detectado por imuno-histoquímica e espectroscopia de ressonância magnética. Atualmente, nenhum medicamento tem como alvo o gene IDH mutado, embora essa ainda seja uma área de pesquisa ativa. ${ }^{10}$

Gliomas de baixo grau são tumores cerebrais que afetam predominantemente adultos jovens. Com potencial de comprometimento da capacidade cognitiva e, em última análise, levar ao óbito. Crescem em taxas mais lentas e tem um prognóstico mais favorável em comparação com gliomas de alto grau. Eles correspondem de 10 a $20 \%$ dos tumores primários do SNC em adultos. ${ }^{3}$ 
Os tumores de Grau I são benignos e na sua maioria curáveis com ressecção cirúrgica completa. Esses tumores ocorrem principalmente em crianças, diferentemente que os de Grau II ao IV, que é visto em adultos. Os tumores Grau II, incluem os: astrocitomas, oligodendrogliomas e oligoastrocitomas ou gliomas mistos. As lesões de Grau II eventualmente progridem para Glioma de alto grau Grau III e IV. Louis et al. (2007) na quarta edição da classificação da Organização Mundial de Saúde (OMS) de tumores do sistema nervoso central, publicada em 2007 basearam-se no consenso de um grupo de trabalho internacional de 25 patologistas e geneticistas, bem como contribuições de 70 especialistas internacionais em geral, e é apresentado como o padrão para a definição de tumores cerebrais para a clínica de oncologia e comunidades de pesquisa de câncer em todo o mundo. Dois grandes estudos de gliomas malignos sugerem que a necrose está associada com pior prognóstico em gliomas anaplásicos com oligodendrogliomas e componentes astrocíticos. Pacientes cujo tumores mostraram necrose apresentaram uma sobrevida substancialmente menor em comparação aos pacientes que não haviam necrose. ${ }^{11}$

Malheiros et al. ${ }^{12}$ (1998) relataram sobre os chamados "gliomas de baixo grau", que correspondem de 10 a 20\% dos tumores primários do SNC em adultos. Esse grupo inclui astrocitomas (mais frequientes), oligodendrogliomas, gliomas mistos (oligoastrocitomas), além de variantes menos comuns de astrocitomas, como o astrocitoma pilocítico, o xantoastrocitma pleomórfico e o astrocitoma subependimário de células gigantes. São tumores que acometem com mais freqüência crianças e adultos jovens, com idade mediana de 37,3 anos na época da apresentação e predomínio no sexo masculino.

A maioria dos casos, $51,6 \%$, é classificado como astrocitoma e 33,5\% e 14,9\% classificados como oligodendroglioma e glioma misto, respectivamente. O glioma continua sendo uma neoplasia pouco conhecida, com alta morbidade e desfecho devastador. ${ }^{13}$

Claus et al. ${ }^{14}$ (2015) descreveram que o Glioma de baixo grau é uma doença uniformemente fatal em adultos jovens (idade média de 41 anos), com média de sobrevida de aproximadamente 7 anos. Embora os pacientes com glioma de baixo grau tenham melhor sobrevida do que os pacientes com glioma de alto grau (Grau III ou IV da OMS), todos os gliomas de baixo grau eventualmente progridem para glioma e morte de alto grau. De acordo com o programa Surveillance, Epidemiology and End Results (SEER) do Instituto Nacional do Câncer, sugere que, para a maioria dos pacientes com Glioma de baixo grau, a sobrevida global não melhorou significativamente nas últimas três décadas, destacando a necessidade de intensificar o estudo desse tumor. Pesquisas recentemente publicadas sugerem que variáveis clínicas historicamente usadas não são suficientes indicadores de prognósticos e preditivos relativos a informações fornecidas por marcadores tumorais recentemente descobertos. A descoberta de tal tumor e variação constitutiva pode identificar variáveis necessárias para melhorar a randomização em ensaios clínicos, bem como identificar pacientes mais sensíveis aos tratamentos atuais e metas para melhorar o tratamento no futuro. 
O esquema de classificação da OMS recomenda que o termo glioma de baixo grau seja revogado pois engloba uma grande variedades de neoplasias gliais de grau I e II, muitas delas com prognóstico, terapia e propriedades biológicas totalmente diferentes. ${ }^{15}$

Pirzkall ${ }^{16}$ (2002) estudou sobre a imagem da espectroscopia de ressonância magnética tridimensional (3D) que tem sido relatada como valiosa na definição da extensão da infiltração de glioma. Vinte pacientes com gliomas supratentorial Grau II da OMS (7 astrocitomas, 6 oligoastrocitomas, 7 oligodendrogliomas) foram submetidos a ressonância magnética antes da cirurgia. As regiões de interesse incluíram hiperintensidade T2 e, se presente, regiões de realce de contraste em imagens ponderadas em T1. O diagnóstico do glioma de baixo grau é feito através de uma combinação de imagens latentes, histopatologia e métodos diagnósticos moleculares. Na tomografia computadorizada, os gliomas de baixo grau aparecem como áreas difusas de baixa atenuação. Desta forma, a ressonância magnética é o exame de escolha para diagnóstico do glioma de baixo grau.

A apresentação clínica de qualquer tumor do SNC poderá variar de acordo com sua localização, mas no geral os sintomas apresentados são de cefaléia, sinais de hipertensão intracraniana decorrentes do efeito expansivo ou de hidrocefalia, ataxia cerebelar - dificuldade do cerebelo em coordenar os movimentos do corpo, sinais piramidais (danos no feixe piramidal, primeiro neurônio motor), déficits focais, náuseas, perda do equilíbrio, muito sono, problemas de visão e audição. A forma de apresentação dos sintomas costuma ser lenta e insidiosa. ${ }^{12}$

A maioria das pessoas com Glioma de baixo grau apresentam convulsões, mudanças de personalidade, dor de cabeça, náuseas e letargia. Os sintomas neurológicos refletem amplamente a localização e o tamanho do tumor. O Glioma de baixo grau frequentemente ocupa lobos frontais e temporais, particularmente a área motora suplementar e ínsular. ${ }^{17}$

Silva et al. ${ }^{18}$ (2007) investigaram as funções cognitivas de pacientes com gliomas de baixo grau antes do tratamento cirúrgico ou medicamentoso. Treze pacientes com glioma de baixo grau foram submetidos à avaliação neuropsicológica com testes psicométricos. Todos os pacientes apresentaram déficit cognitivos em mais de duas funções cognitivas, sendo memória episódica verbal e funções executivas as mais prejudicadas. Oito pacientes (62\%) apresentaram déficit grave de memória episódica verbal imediata, sete $(54 \%)$ de tardia e quatro (31\%) de reconhecimento. Quanto às funções executivas, $92 \%$ dos pacientes apresentaram déficit de fluência verbal nominal e $77 \%$ de fluência verbal categórica, variando entre leve e grave, $85 \%$ dos pacientes apresentaram déficit de flexibilidade mental e de velocidade de processamento de informações. Demonstraram a importância de submeter esta população de pacientes à avaliação neuropsicológica antes do tratamento para que, assim, os resultados obtidos possam direcionar o tratamento de forma mais efetiva, minimizando possíveis conseqüências funcionais para o paciente. 
Chang et al. ${ }^{19}$ (2008) relataram sobre as convulsões e o papel importante que desempenham na apresentação clínica e na qualidade de vida pós-operatória de pacientes submetidos à ressecção cirúrgica de gliomas de baixo grau. Os autores realizaram uma revisão retrospectiva de todos os casos envolvendo pacientes adultos que foram submetidos a cirurgia inicial para glioma de baixo grau na Universidade da Califórnia, San Francisco entre 1997 e 2003, que resultou em 332 casos incluídos para análise sendo 269 $(81 \%)$ dos 332 pacientes apresentaram com convulsões. Em aproximadamente metade desses pacientes, as convulsões são farmacorresistentes antes da cirurgia. No pós-operatório, $90 \%$ desses pacientes estão livres de crises ou apresentam melhora significativa. Uma história mais curta de convulsões e ressecção totalbruta parece estar associada a um prognóstico para controle de crises.

Os principais sintomas do glioma de baixo grau são convulsões, cefaleias e náuseas. Os outros sinais e sintomas dependem da localização do tumor como: disartria, falta de força e alteração de comportamento no lobo frontal, alterações na linguagem e na visão no lobo temporal, alterações na visão no lobo occipital, defeitos sensoriais e visuais no lobo parietal, hipertensão intracraniana decorrente de hidrocefalia no cerebelo. Em termos de frequência dos sintomas, os mais observados são: cefaleias (37\%), sintomas oculovisuais $(25 \%)$, vômitos $(18 \%)$, convulsões $(15 \%)$, alterações da marcha (15\%) e déficits motores $(11 \%) .{ }^{20}$

O glioma de baixo grau tem como tratamento de eleição a remoção cirúrgica total, associada à uma sobrevida livre de progressão aos 5 anos, de 97\%. Se o tumor for totalmente removido, o prognóstico é excelente. Por outro lado, se o tumor não é ressecável, tem de se optar por uma das armas terapêuticas oncológicas, que não garantem um prognóstico tão favorável, seja por recorrência da doença ou por toxicidade do tratamento. Nos casos em que o glioma não pode ser totalmente removido, o tratamento fica limitado ao uso de radioterapia ou de quimioterapia. A radioterapia proporciona sobrevidas livres de progressão aos 5 anos, na ordem dos 70\%, mas provoca uma toxicidade considerável no tecido cerebral dos pacientes, em fundamental para o correto desenvolvimento do SNC. A quimioterapia é responsável por uma menor toxicidade, mas nenhum dos vários regimes de quimioterapia usados permite sobrevidas livres de progressão aos 5 anos, superiores a 60\%. As novas terapias moleculares dirigidas aos gliomas de baixo grau trouxeram a promessa de diminuir a toxicidade dos tratamentos e ainda de superarem a eficácia dos tratamentos oncológicos atuais, porém, serão necessários muitos estudos para se comprovar a eficácia destes novos agentes dirigidos a alvos moleculares específicos. ${ }^{7}$

A ressecção total da lesão é a única modalidade de tratamento para o glioma de baixo grau que não é objeto de controvérsia. Na neuro-oncologia cirúrgica tão importante quanto a quantidade do tumor removido, é o quanto é deixado para trás. Se a radioterapia for necessária, o volume menor a se irradiar, minimiza os efeitos cognitivos tardios da radioterapia. ${ }^{21}$

Nos últimos anos, estudos indicaram que o sangue vascular do tumor é a base morfológica do crescimento do tumor e da metástase. Vasos sangüíneos tumorais não apenas fornecem nutrição para as 
células tumorais, mas também continuamente fornecem células tumorais para outras partes do corpo, levando ao crescimento e metástase de tumores malignos. Dados pré-clínicos e clínicos indicam que as terapias antiangiogênicas são potenciais em glioblastoma e pode transitoriamente normalizar vasos tumorais. Isso cria uma janela de oportunidade para otimizar a combinação de quimioterápicos e radiação. Hoje em dia, para alguns pacientes com glioma, a terapia de ressecção cirúrgica foi substituída por diagnóstico e tratamento abrangente da biologia molecular, que abrange o profilático, o teste, o diagnóstico e posteriormente o tratamento do glioma. ${ }^{9}$

A maioria dos pacientes com Glioma de baixo grau é tratado inicialmente com ressecção cirúrgica seguido de biópsia para confirmação de diagnóstico. E após cirurgia pode ser tratado com radioterapia e/ou quimioterapia. Essa é a terapia trimodal. ${ }^{14}$

A cirurgia é o tratamento inicial do Glioma, pois tem o objetivo de fazer a máxima ressecção cirúrgica e preservar a função neurológica do paciente. É mais recomendado a ressecção cirúrgica macroscópica total do que a ressecção subtotal, pois a primeira prolonga a sobrevida dos pacientes. ${ }^{22}$

Ramina et al. ${ }^{23}$ (2005) analisaram retrospectivamente 8 pacientes com astrocitoma de baixo grau na região tectal operados entre 1981 e 2002. A idade média foi 16,6 anos (variando de 8 a 44 anos). Todos os pacientes apresentaram hidrocefalia e um desvio (shunt) foi colocado em todos antes da remoção cirúrgica da lesão. A lesão tumoral foi removida completamente em 7 dos 8 casos. Em um único caso a remoção total foi impossível devido ao caráter infiltrativo do tumor. Radioterapia pós operatória foi indicada em 2 casos, o primeiro no início da série e o segundo caso com tumor de caráter infiltrativo. Este último paciente apresentou crescimento tumoral progressivo e veio a falecer 5 anos após a cirurgia. Nos demais 7 pacientes não houve recorrência tumoral. $O$ tempo de acompanhamento foi 2,5 a 22,5 anos. A remoção microneurocirúrgica radical pode e deve ser sempre cogitada em pacientes com tumores não-invasivos, pois a baixa morbidade - mortalidade é possível e aceitável, além do procedimento poder ser curativo.

A radioterapia tem o objetivo de induzir a morte celular através dos efeitos diretos da radiação. Esse efeito faz com que a sua própria energia cause alterações no DNA. Porém outros efeitos danificam o DNA celular pelos radicais livres provenientes da quebra molecular de água, causando oxidação e dano celular. A radioterapia em câncer de cabeça e pescoço tem sua aplicabilidade e eficácia em função de parâmetros como tipo histológico da neoplasia, do local e do volume da área a ser irradiada, dose, ritmo de aplicação, tipo de radiação e condições gerais do paciente. ${ }^{24}$

Os procedimentos de radioterapia são considerados um dos mais efetivos, isoladamente ou complementando tratamentos cirúrgicos ou quimioterápicos. A radioterapia intersticial ou braquiterapia ou radiocirurgia intersticial é um procedimento que possibilita a aplicação de elevada dose de radiação limitada a volumes definidos de tumores, com pouco comprometimento dos tecidos adjacentes. Apesar de ser aplicado desde o início do século XX, somente nos últimos 25 anos esse procedimento tornou-se uma 
alternativa atraente e é praticado em algumas unidades de radioterapia e de neurocirurgia. A radioterapia intersticial consiste na irradiação intralesional, com taxas de doses variadas. A possibilidade de irradiação com baixa taxa de dose e elevada dose total são algumas vantagens da radioterapia intersticial sobre a telerradioterapia convencional. A radioterapia intersticial é um método que possibilita tratar lesões neoplásicas com irradiação sem comprometer expressivamente o tecido localizado nas suas vizinhanças. ${ }^{25}$

A radioterapia tem um papel fundamental no controle local da doença, sendo a dose de 60 Gy já instituída de forma rotineira. Doses de até 72 Gy em esquemas hiperfracionados não demonstraram ser superiores aos esquemas tradicionais. O hipofracionamento tem sido bem estudado nos casos de pacientes mais idosos ou com Karnofsky Performance Scale (KPS) inferior a 60 com resultados satisfatórios, alcançando diminuição do tempo de tratamento. Infelizmente, a técnica radiocirúrgica se aplica a doenças localizadas, com margem e tamanhos bem definidos, e com objetivo secundário de se atingir doses seguras e não deletérias ao tecido cerebral normal. Os gliomas de alto ou baixo grau são doenças intra-axiais infiltrativas, com bordos muito mal definidos, com alto potencial de diferenciação e frequentemente de volumes e tamanhos elevados. Com isso, é frequente não conseguir atingir a dose terapêutica adequada, devido à alta taxa de dose no parênquima normal ou estruturas mais radiossensiveis, tais como tronco encefálico e aparato óptico. Por essas razões, existe uma grande dificuldade técnica e fisiopatológica de se indicar o tratamento radiocirúrgico nos casos de gliomas. ${ }^{26}$

Em 2015, Sarmiento, Venteicher e Patil realizaram um estudo incluindo ensaios clínicos randomizados que compararam a radioterapia precoce versus tardia após biópsia ou ressecção cirúrgica para o tratamento de pessoas com glioma de baixo grau intracraniano recentemente diagnosticado (astrocitoma, oligodendroglioma, oligoastrocitoma misto, astroblastoma, xantoastrocitoma ou ganglioglioma). Três revisores avaliaram independentemente os estudos para inclusão e risco de viés e extraíram os dados do estudo. Este estudo descobriu que a radioterapia pós-operatória precoce está associada a um aumento no tempo de progressão em comparação com a observação e atraso na radioterapia após a progressão da doença para pessoas com glioma de baixo grau, mas não melhora significativamente a sobrevida global. A média de sobrevida livre de progressão foi de 5,3 anos no grupo de radioterapia precoce e 3,4 anos no grupo de radioterapia tardia. A média da sobrevida global no grupo de radioterapia precoce foi de 7,4 anos, enquanto o grupo de radioterapia tardia apresentou sobrevida global média de 7,2 anos. A dose total de radioterapia administrada foi de $54 \mathrm{~Gy}$; cinco frações de 1,8 Gy por semana foram dadas por seis semanas. Os efeitos adversos após a radioterapia consistiram em reações cutâneas, otite média, cefaleia leve, náuseas e vômitos. A terapia de resgate foi fornecida a $65 \%$ dos participantes randomizados para radioterapia tardia. As pessoas que estavam livres de progressão tumoral não mostraram diferenças no déficit cognitivo, déficit focal, status de desempenho e cefaleia após um ano. No entanto, os participantes randomizados para o grupo de radioterapia precoce experimentaram significativamente menos 
convulsões do que os participantes no grupo de radioterapia pós-operatória tardia em um ano. Conclui-se que a radioterapia precoce foi associada aos seguintes efeitos adversos: reações cutâneas, otite média, cefaléia leve, náuseas e vômitos. Pessoas com glioma de baixo grau que se submetem a radioterapia precoce mostraram um aumento no tempo de progressão em comparação com pessoas que foram observadas e tiveram radioterapia no momento da progressão. Não houve diferença significativa na sobrevida global entre pessoas que tiveram início precoce versus radioterapia tardia. As pessoas que foram submetidas à radiação precoce tiveram melhor controle das crises em um ano do que as que sofreram radiação tardia. No entanto, ainda não está claro se existem diferenças na memória, função executiva, função cognitiva ou qualidade de vida entre os dois grupos, uma vez que essas medidas não foram avaliadas. ${ }^{3}$

Cardoso et al. ${ }^{24}$ (2005) verificaram a condição bucal dos pacientes atendidos no setor de Cirurgia de Cabeça e Pescoço submetidos a cirurgia associada à radioterapia ou a radioterapia exclusiva, com o objetivo de visualizar as possíveis alterações nas diversas fases do tratamento e prevenir, diagnosticar e controlar lesões do complexo maxilo-mandibular resultantes dos procedimentos cirúrgico e radioterápico. Foi feito avaliação de 42 pacientes, de ambos os sexos, com idade entre 37 e 70 anos, portadores de neoplasias malignas de cabeça e pescoço, no Serviço de Cirurgia de Cabeça e Pescoço da Disciplina de Otorrinolaringologia da Universidade Federal de São Paulo/Escola Paulista de Medicina (Unifesp/EPM), submetidos a radioterapia. Do total de 42 pacientes, 12 foram acompanhados para a elaboração do estudo, tendo como critério de elegibilidade o cumprimento total das etapas propostas: tratamento odontológico antes do início da radioterapia, acompanhamento semanal durante o transcorrer da radioterapia e acompanhamento de no mínimo seis meses após seu término. A dermatite ocorreu em todos os pacientes, tendo sido observada a partir da segunda semana do início da Radioterapia. A xerostomia teve sua presença em todos os pacientes durante todo o período do desenvolvimento deste trabalho. Cinco dos 12 pacientes apresentaram candidíase clínica. As alterações do paladar ocorreram em todos os pacientes em diferentes graus, atingindo a proporção máxima por volta da sexta semana. A disfagia foi relatada por 11 dos 12 pacientes acompanhados, sendo que somente em dois houve gravidade que exigiu a colocação de sonda nasogástrica. Não foi observado a presença de cáries e nem presença de trismo. O não aparecimento de osteorradionecrose também foi visto e esperado pois os principais fatores predisponentes foram bem controlados. No período durante a radioterapia os pacientes apresentaram queda no estado geral, porém com o término do tratamento foi verificado melhora considerável no estado geral dos pacientes. Concluise que prevenindo e controlando as seqüelas induzidas pela ação da irradiação no tratamento de neoplasias da região de cabeça e pescoço, estaremos também possibilitando melhoria na qualidade de vida desses pacientes.

Em 2018, com o objetivo de avaliar a saúde bucal de pacientes com câncer de cabeça e pescoço após tratamento antineoplásico, e compará-los com pacientes sem histórico de câncer, Quispe et al. ${ }^{27}$, 
realizaram um estudo transversal com indivíduos de ambos sexos, maiores de 18 anos de idade, divididos em Grupo de Estudo (GE) e Grupo Controle (GC). O GE foi composto por pacientes com câncer de cabeça e pescoço após concluir o tratamento que incluiu cirurgia, radioterapia e/ou quimioterapia. Foram avaliados 75 indivíduos, sendo 30 no GE e 45 no GC. Em relação à prevalência de cárie dentária (índice CPOD), foi obtida média de 24,43 para o GE e de 25,24 para o GC, sem diferença estatística significativa. O índice de doença periodontal revelou maior prevalência no GE (96,7\%) comparada ao GC (60\%). O GE apresentou maior presença de cálculos $(33,3 \%)$, seguida por bolsa rasa $(26,7 \%)$ frente ao GC $(40 \%)$, que apresentou maior número de indivíduos sem sinais clínicos de doença periodontal. Neste estudo, não houve diferença estatística significativa na prevalência de cárie dentária entre GE e GC, porém a doença periodontal foi mais prevalente no GE, com $90,7 \%$, diante de $60 \%$ do GC. Os tecidos periodontais podem sofrer mudanças após o tratamento, podendo acontecer recessão gengival, perda de inserção gengival e elevado índice de placa bacteriana. A saúde oral dos indivíduos com câncer de cabeça e pescoço é afetada após o tratamento antineoplásico. Entre as estruturas dentárias e periodontais, as últimas apresentam maiores danos após o tratamento antineoplásico.

O tratamento medicamentoso é feito através de agentes quimioterápicos: as nitrosureias e a temozolomida. Trata-se de agentes alquilantes que apresentam ação anti-tumoral e são os mais utilizados hoje em dia. ${ }^{5}$

Choucar ${ }^{21}$ (2017) avaliou 254 pacientes com glioma de baixo grau de alto risco que foram randomizados para radioterapia com ou sem quimioterapia adjuvante. Dos pacientes que tiveram melhores resultados, mais de $70 \%$ foram tratados com quimioterapia. A terapia de combinação imediata resultou em um ganho de 10,4 versus 4,0 anos. Este ensaio demonstrou que, quando se decide proceder à radioterapia, seria preferível que a quimioterapia adjuvante fosse utilizada imediatamente após a conclusão da radioterapia, em vez de esperar para iniciar a quimioterapia durante o tempo de progressão. Vivemos na era da medicina personalizada, com ênfase na tomada de decisões compartilhadas entre médico e paciente. Os objetivos centrados no paciente são para melhorar a qualidade e tempo de vida, minimizar a toxicidade e proteger a função neurocognitiva. Conclui que essas metas e objetivos centrados no paciente são melhor perseguidos quando os pacientes são inscritos em ensaios clínicos.

Buckner et al. ${ }^{28}$ (2016) demonstraram que o tratamento com procarbazina, lomustina e vincristina após a radioterapia no momento do diagnóstico inicial resultou em maior sobrevida livre de progressão, mas não sobrevida global, do que a radioterapia isolada. Foram incluídos pacientes com astrocitoma grau 2, oligoastrocitoma ou oligodendroglioma com idade inferior a 40 anos e submetidos à ressecção subtotal ou biópsia ou que tinham 40 anos ou mais e haviam sido submetidos a biópsia ou ressecção de qualquer tumor. Os pacientes foram estratificados de acordo com a idade, achados histológicos, escore de status de desempenho de Karnofsky e presença ou ausência de realce de contraste em imagens pré-operatórias. Os 
pacientes foram aleatoriamente designados para a radioterapia isolada ou para a radioterapia, seguida por seis ciclos de quimioterapia combinada. Um total de 251 pacientes elegíveis foram inscritos de 1998 a 2002. O acompanhamento foi de 11,9 anos, sendo que 55\% dos pacientes morreram. Os pacientes que receberam radioterapia mais quimioterapia tiveram sobrevida global media mais longa do que aqueles que receberam apenas radioterapia (13,3 anos versus 7,8 anos). A taxa de sobrevida livre de progressão em 10 anos foi de $51 \%$ no grupo que recebeu radioterapia mais quimioterapia versus $21 \%$ no grupo que recebeu apenas radioterapia. As taxas correspondentes de sobrevida global em 10 anos foram de $60 \%$ para quem recebeu radioterapia mais quimioterapia e $40 \%$ no grupo que recebeu apenas radioterapia. Em uma coorte de pacientes com glioma de grau 2 com menos de 40 anos de idade e submetidos a ressecção subtotal do tumor ou com 40 anos de idade ou mais, a sobrevida livre de progressão e a sobrevida global foram maiores entre aqueles que receberam quimioterapia combinada com radioterapia do que entre aqueles que receberam apenas radioterapia.

\section{DESCRIÇÃO DO CASO CLÍNICO}

Paciente sexo masculino, 22 anos, estudante, natural de Tadepalligudem, sul da Índia. Deu entrada no Pronto-socorro do Mallareddy Narayana Multi Speciality Hospital dia 31/01/2017 com queixa de cefaléia e vômitos incoercíveis. Negava sintomas neurológicos prévios. Ao exame neurológico, encontravase sonolento, porém orientado no tempo e espaço, obedecendo aos comandos verbais, com linguagem preservada. Foi submetido à exame de Ressonância Nuclear Magnética (RNM) de crânio no mesmo dia, que observou: imagem espontaneamente hiperdensa frontal direita, com massa de tamanho aproximado de 4,2 x 4,8 x 3,2 cm com desvio da linha média de $11 \mathrm{~mm}$ para região sagital, com discreto efeito expansivo e edema.

Em 03/02/2017 o paciente foi submetido à craniotomia frontal direita no Mallareddy Narayana Multi Speciality Hospital. O estudo anatomopatológico descreveu glioma de baixo grau.

O paciente foi encaminhado para tratamento radioterápico no Basavatarakam Indo-american Cancer Hospital \& Research Institute que se deu em 23 sessões, com duração de 6 semanas no período de 08/03/2017 a 21/04/2017. Recebeu 6 MV de radioterapia externa de raios-X photon beam para o cérebro totalizando 54 Gy, sendo 180 cGy por fração, na técnica IMRT de radioterapia. Com adequada tolerância ao tratamento, entretanto apresentou descamação de pele local, leve perda de cabelos e episódios de cefaléia. Em relação à condição bucal, não foi verificado xerostomia, disfagia, candidíase, alteração no paladar, trismo, cárie de radiação, doença periodontal e osteorradionecrose. Em 06/12/2017 foi realizada radiografia panorâmica em que observou-se ausência de cáries de radiação, doença periodontal e osteorradionecrose (Figura 1). 
Após as sessões de radioterapia os médicos sugeriram esperar alguns meses para nova RNM de crânio, que foi realizada em 5 meses detectando recidiva do tumor cerebral. O paciente foi encaminhado para nova craniotomia com ampliação de margem de segurança, porém teve que aguardar alguns meses pois foi encaminhado para o hospital do governo.

Por não apresentar evolução satisfatória, em 15/03/2018 no Guntur Government General Hospital o paciente foi submetido à craniotomia frontal direita, e após 2 meses evoluiu com edema na região frontal direita e extravasamento de líquido cefalorraquidiano (Figura 2).

Após alguns dias, o paciente buscou outras opiniões médicas, que sugeriram realização de cranioplastia para fixação da calota craniana e recobrimento da massa encefálica. Em 06/07/2018, no Himagiri Hospital, o paciente foi submetido à cranioplastia com uso de parafusos de titânio para fixação da calota craniana (Figura 3). Em uma semana da cirurgia, o paciente apresentou edema frontal direito, foi submetido a drenagem de líquido cefalorraquidiano e prescrito levetiracetam $500 \mathrm{mg}$ e acetazolamida 250 mg como tratamento adjuvante.

O paciente realizou em 2 meses nova RNM do crânio e não foi encontrado tumor cerebral, porém o mesmo continuou com descamação de pele local e leve perda de cabelos (Figura 4).

Em 16/09/2019 foram realizadas radiografias panorâmica (Figura 5) e telerradiografias frontal (Figura 6) e lateral (Figura 7) para controle das condições bucais, que se mantêm as mesmas, e presença da calota craniana fixada com parafusos de titânio.

Atualmente, o paciente se encontra assintomático, nega uso de medicação contínua e refere não ter sofrido nenhuma implicação bucal após o seu tratamento radioterápico para glioma de baixo grau (Figura 8).

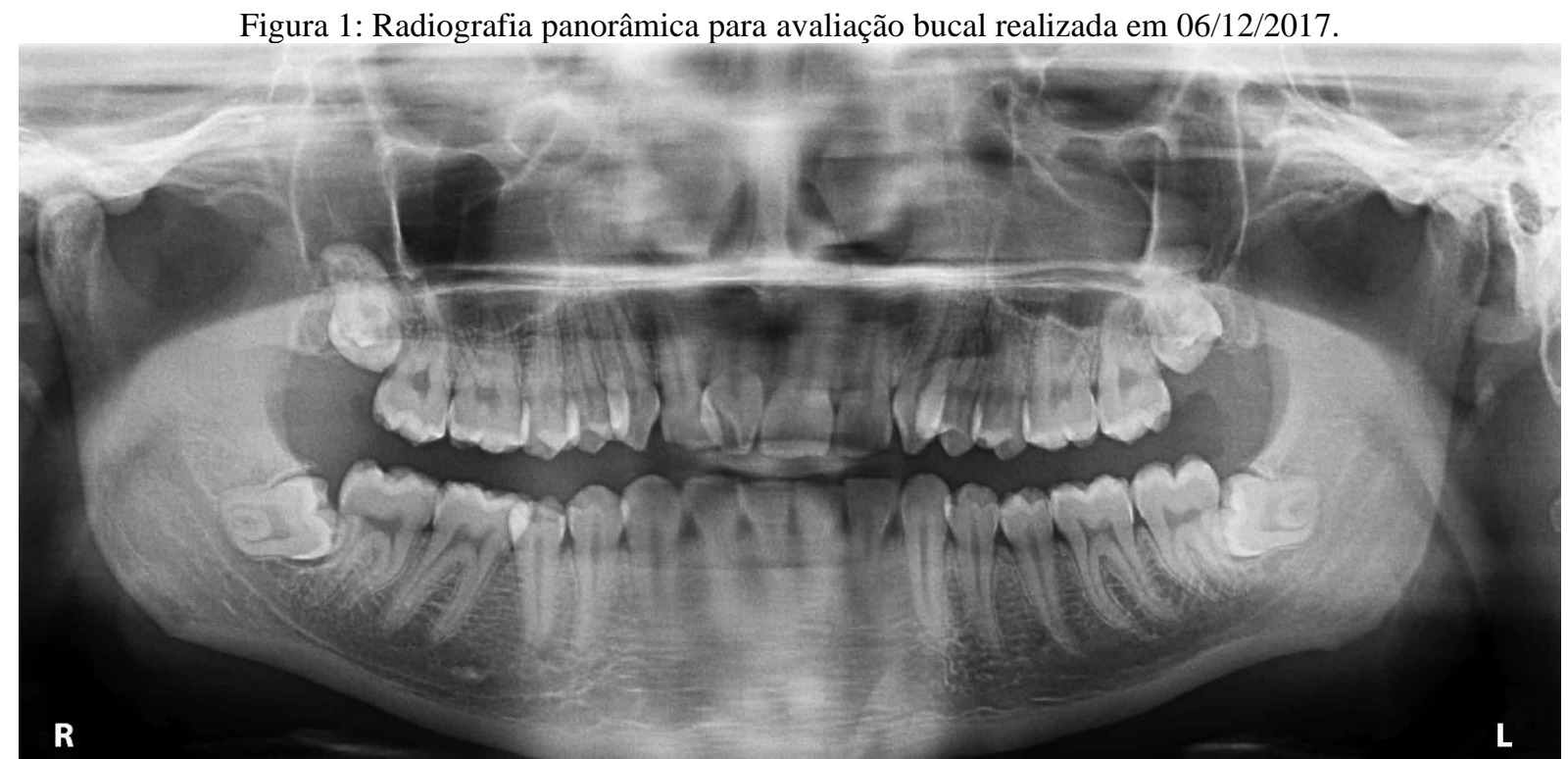


Figura 2: Foto demonstrando edema na região frontal direita em maio de 2018

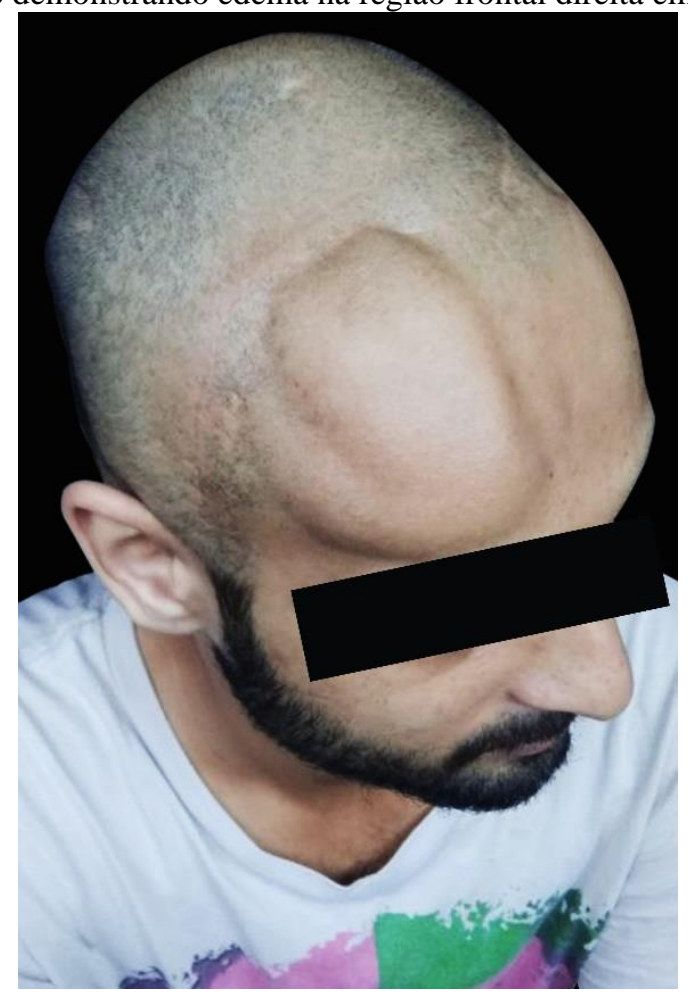

Figura 3: Foto após a cirurgia de cranioplastia em Julho de 2018

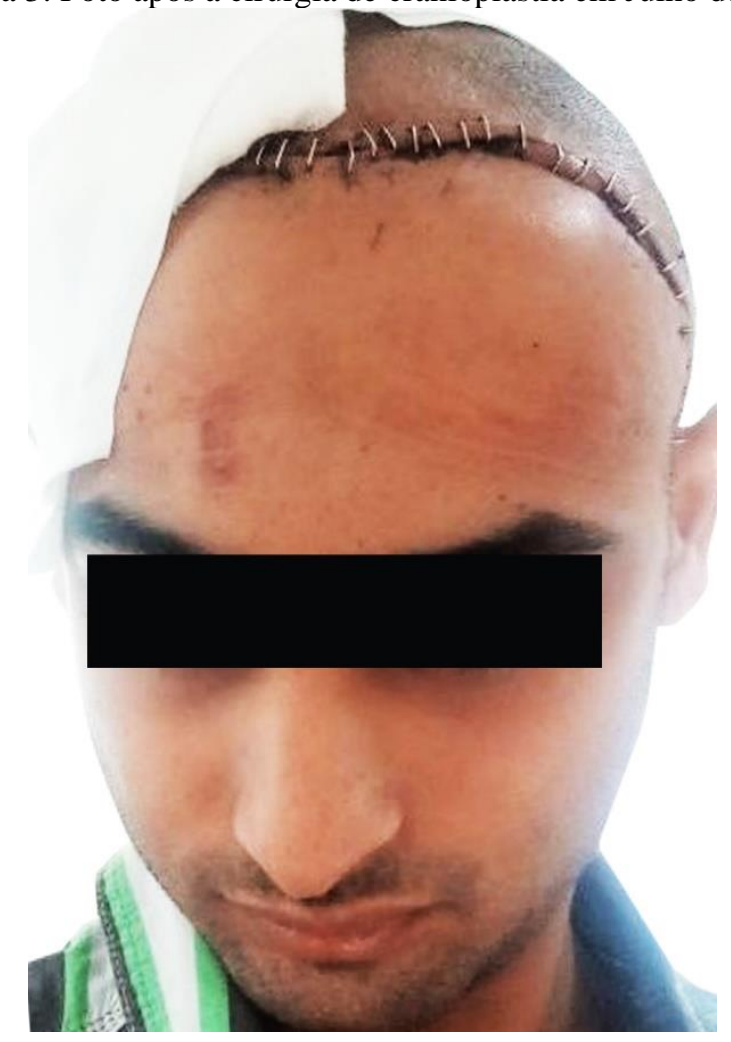




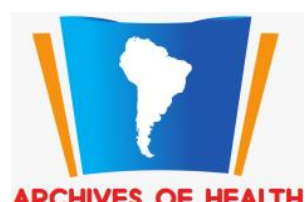

Figura 4: Foto demonstrando descamação de pele local e leve perda de cabelos em setembro de 2018.

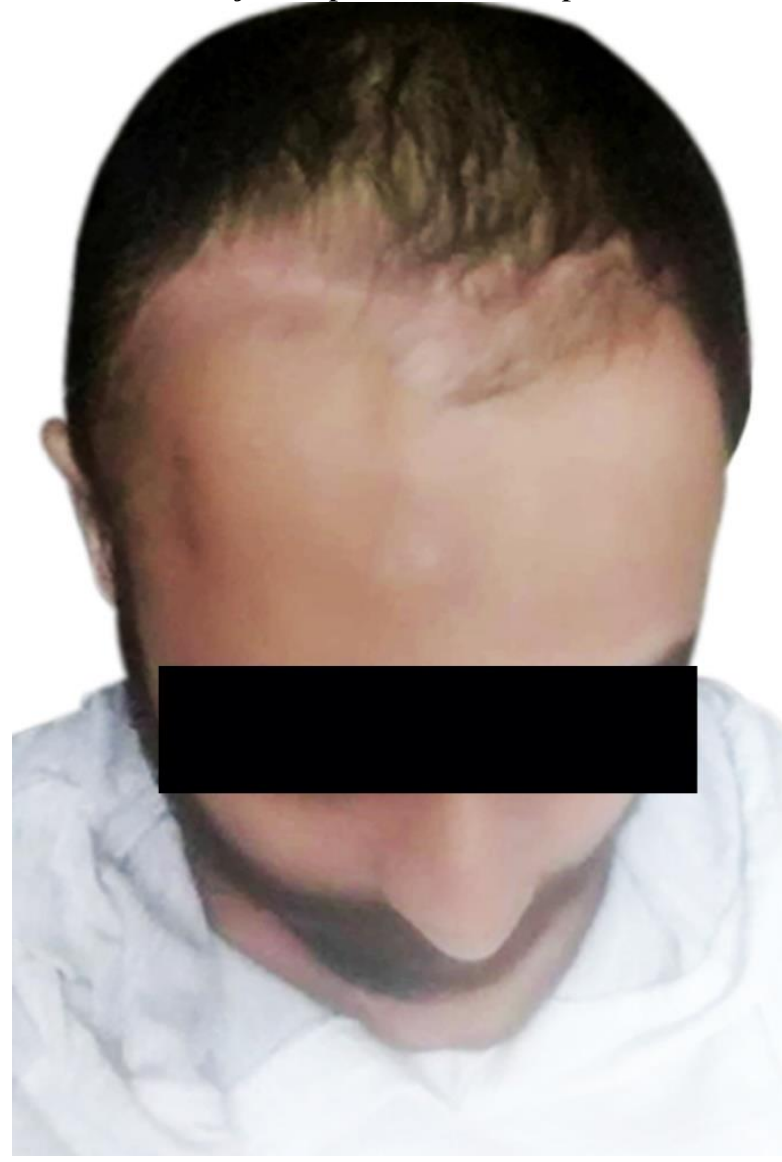

Figura 5: Radiografia panorâmica para avaliação bucal realizada em 16/09/2019.

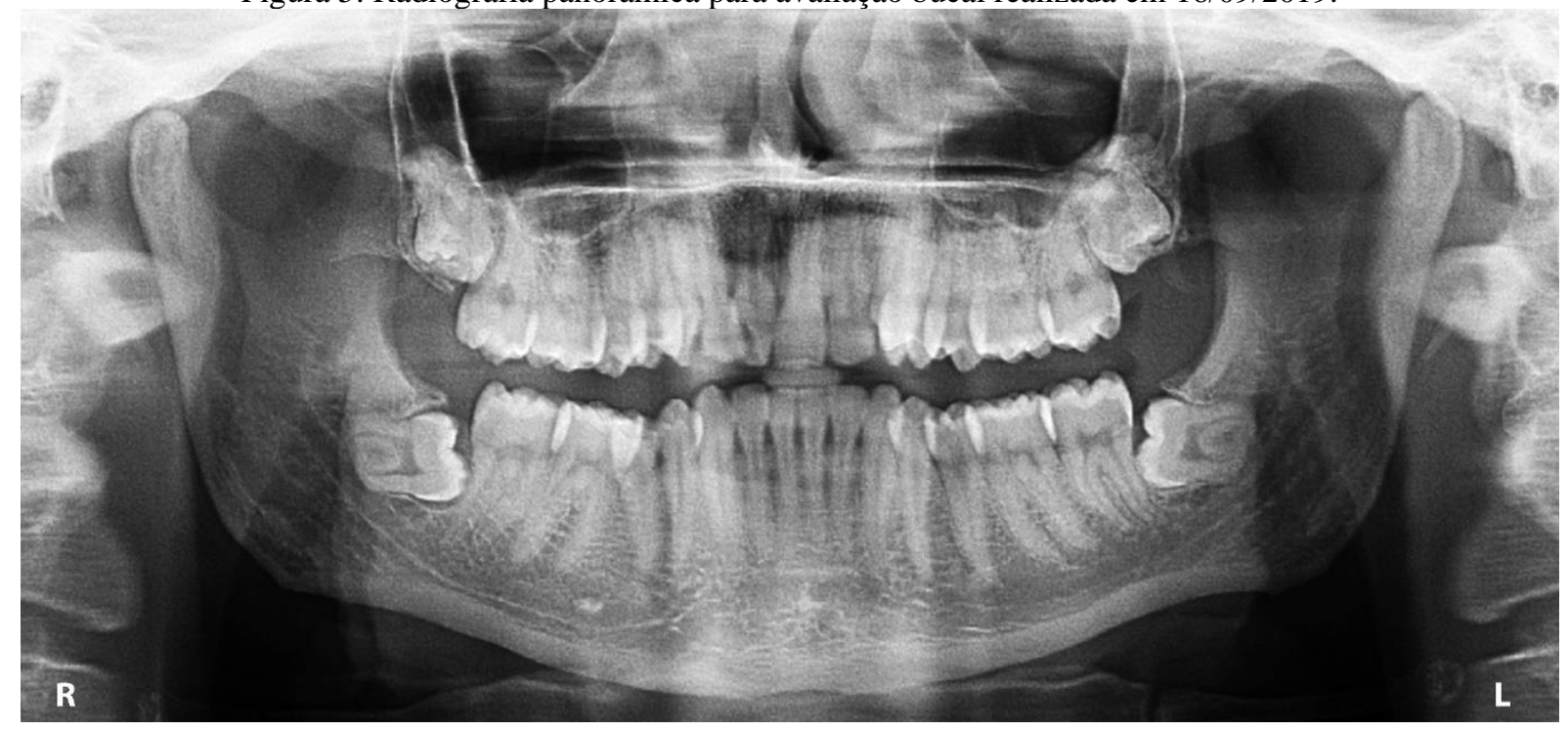




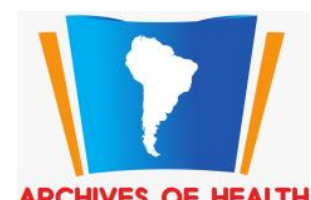

Figura 6: Teleradiografia frontal demonstrando presença da calota craniana fixada com parafusos de titânio realizada em 16/09/2019.

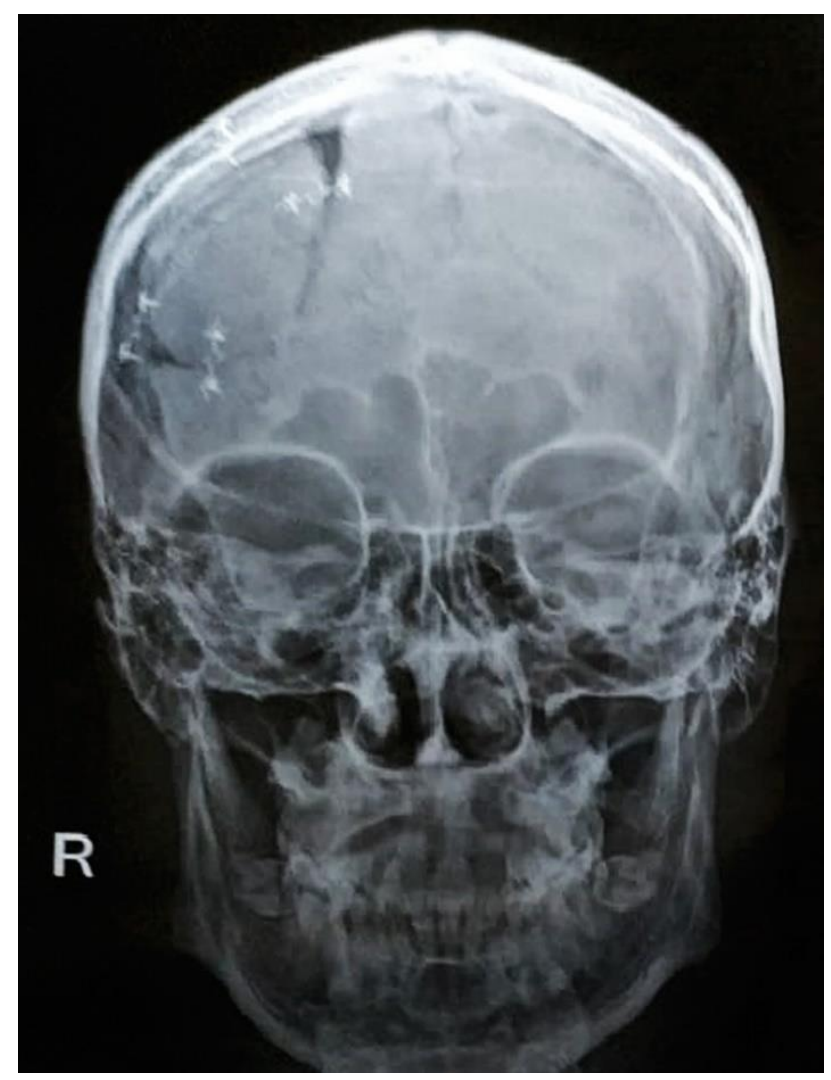

Figura 7: Teleradiografia lateral demonstrando presença da calota craniana fixada com parafusos de titânio realizada em 16/09/2019.

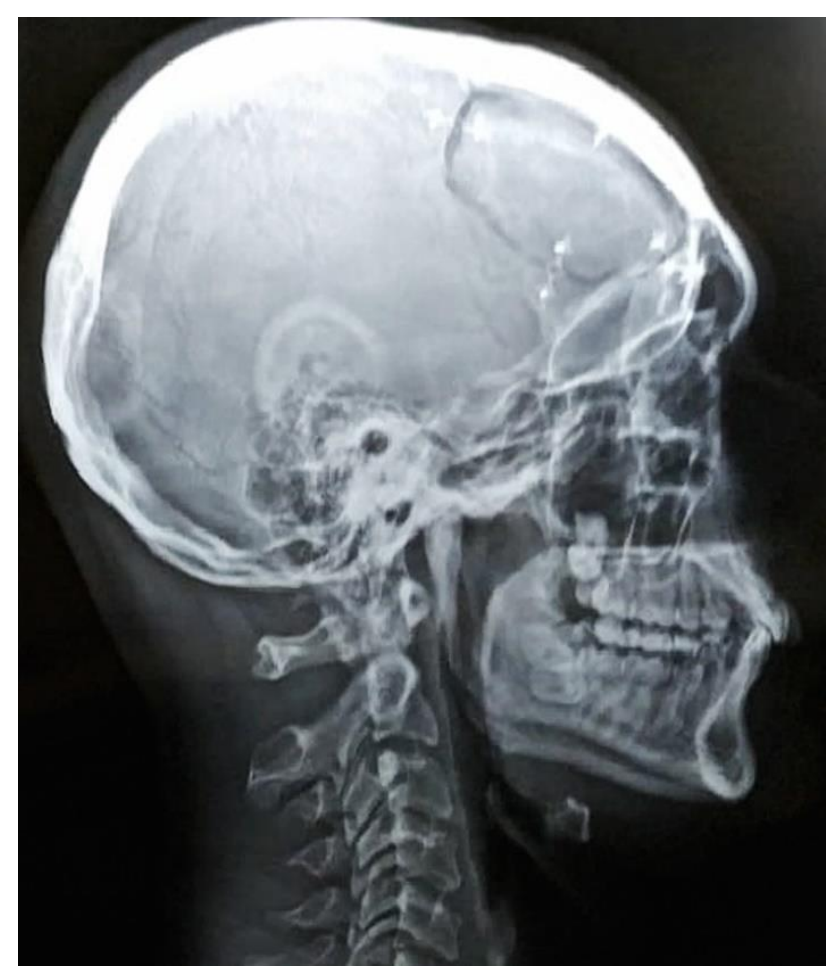




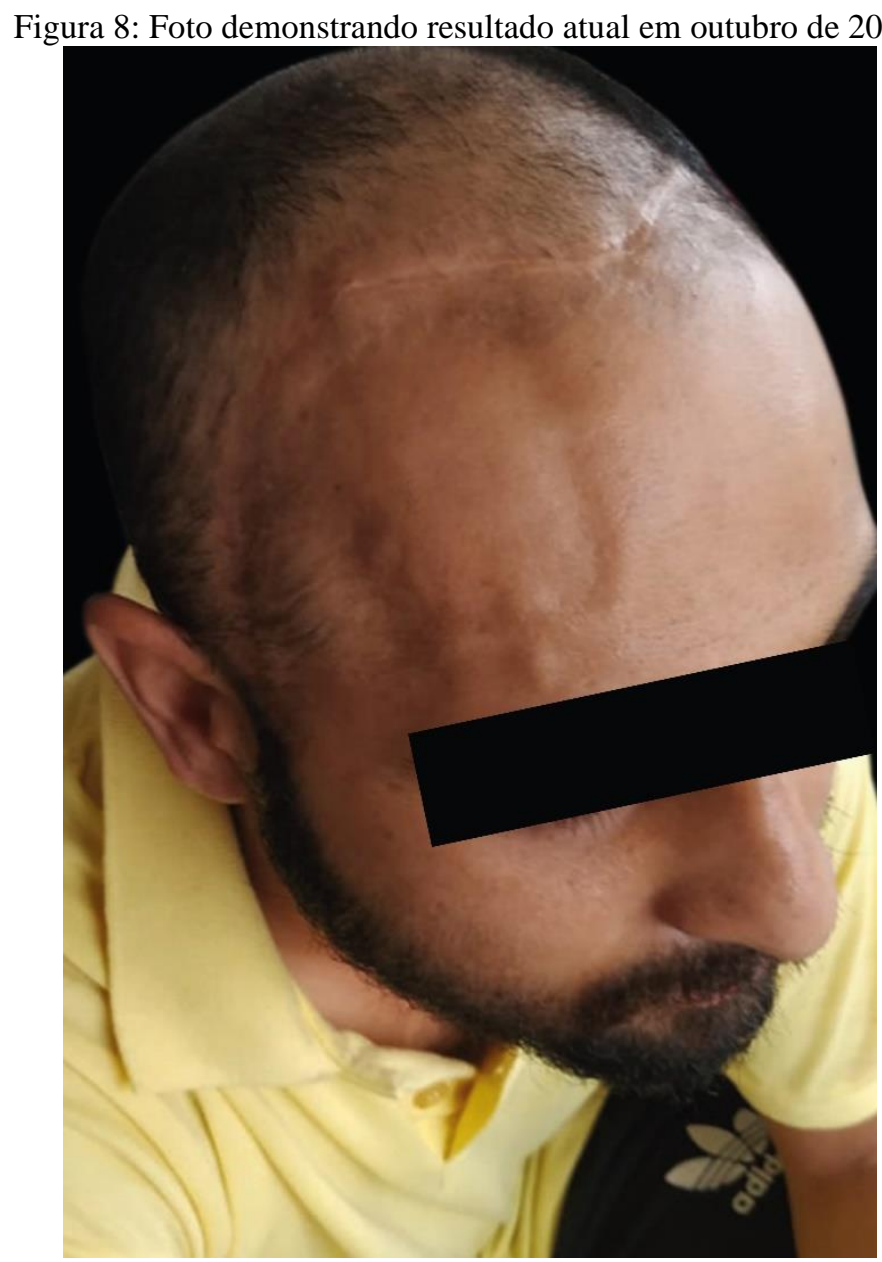

\section{DISCUSSÃO}

O tratamento atual dos gliomas de baixo grau inclui a remoção cirúrgica, no caso de tumores ressecáveis e o tratamento com quimioterapia, em primeira linha, ou radioterapia, em segunda linha, no caso de tumores irressecáveis. Se o tumor for totalmente removido, o prognóstico é excelente. Por outro lado, se o tumor não é ressecável, tem de se optar por uma das alternativas terapêuticas oncológicas mencionadas, que não garantem um prognóstico tão favorável, seja por recorrência da doença ou por toxicidade do tratamento. ${ }^{7}$ A ressecção total da lesão é a única modalidade de tratamento para o glioma de baixo grau que não é objeto de controvérsia. ${ }^{21} \mathrm{O}$ paciente relatado realizou inicialmente uma craniotomia frontal direita e após a cirurgia, 23 sessões de radioterapia no período de 6 semanas, totalizando 54 Gy, na técnica IMRT de radioterapia. Com a recidiva do tumor foi realizada novamente uma craniotomia frontal direita que após 2 meses evoluiu com edema na região frontal direita e extravasamento de líquido cefalorraquidiano. Outras opiniões médicas sugeriram realização de cranioplastia com uso de parafusos de titânio para fixação da calota craniana.

Sarmiento et $a l^{3}$ concluíram que pacientes que se submeteram a radioterapia precoce para o tratamento do glioma de baixo grau mostraram um aumento no tempo de progressão do tumor em 
comparação aos pacientes que se submeteram a radioterapia no momento da progressão do tumor. Os pacientes que foram submetidos à radiação precoce tiveram melhor controle das crises em um ano do que os que sofreram radiação tardia. A dose total de radioterapia administrada no estudo de Sarmiento et al. foi de 54 Gy em cinco frações de 1,8 Gy por semana no período de seis semanas. Para Coelho Neto $^{26}$ a radioterapia tem um papel fundamental no controle local da doença, sendo a dose de 60 Gy já instituída de forma rotineira. No caso clínico relatado, o paciente se submeteu à radioterapia logo após o tratamento cirúrgico, realizou 23 sessões de radioterapia no período de 6 semanas totalizando 54 Gy, na técnica IMRT de radioterapia, concordando com o estudo de Sarmiento et al. ${ }^{3}$

Os efeitos adversos encontrados no estudo de Sarmiento et al. ${ }^{3}$ após radioterapia foram reações cutâneas, otite média, cefaléia leve, náuseas e vômitos. Não houve diferença significativa na sobrevida global entre pessoas que tiveram início precoce versus radioterapia tardia. No entanto, ainda não está claro se existem diferenças na memória, função executiva, função cognitiva ou qualidade de vida entre os dois grupos, uma vez que essas medidas não foram avaliadas. Silva et $a l .{ }^{18}$ demonstraram a importância de submeter esta população de pacientes à avaliação neuropsicológica antes do tratamento para que, assim, os resultados obtidos possam direcionar o tratamento de forma mais efetiva, minimizando possíveis conseqüências funcionais para o paciente. O paciente relatado apresentou leve perda de cabelos e alguns episódios de cefaléia.

Para Silva e Aguiar ${ }^{4}$ a maioria dos pacientes apresentou deterioração cognitiva, sintomas físicos e disfunção emocional que invariavelmente interferem nas suas atividades diárias. Os resultados encontrados no estudo de Silva et al. ${ }^{18}$ mostraram um prejuízo importante das funções executivas e de memória episódica verbal em todos os pacientes, independentemente da localização da lesão, após serem submetidos a uma intervenção cirúrgica ou medicamentosa. Nesse estudo, 62\% dos pacientes apresentaram déficit grave de memória episódica verbal imediata, 54\% déficit grave de memória episódica verbal tardia e $31 \%$ déficit grave de memória episódica verbal de reconhecimento. Quanto às funções executivas, 92\% dos pacientes apresentaram déficit de fluência verbal nominal, $77 \%$ de fluência verbal categórica, variando entre leve e grave e $85 \%$ dos pacientes apresentaram déficit de flexibilidade mental e de velocidade de processamento de informações. O paciente do presente estudo logo após a intervenção cirúrgica apresentou um leve déficit de memória, principalmente após a segunda craniotomia. Porém com o passar do tempo, o mesmo relata que não houve comprometimento do seu grau de memória geral, déficit verbal e mental.

De acordo com Gomes et al. ${ }^{5}$ no comparativo entre tratamento cirúrgico, radioterapia e o tratamento medicamentoso, observou-se uma sobrevida em dois anos de 10,9\% no grupo que recebeu apenas radioterapia, enquanto que o grupo que usava a droga temozolomida foi de 27,2\%. O tratamento instituído como padrão-ouro consiste na radioterapia pós-operatória com o uso diário da temozolomida. Já para Wang e Li $^{9}$ existe uma visão geralmente positiva em relação à terapia combinada com nimotuzumabe e 
quimioterapia, de modo que os dois possam se beneficiar. A quimioterapia pós-operatória poderia melhorar os resultados dos pacientes com glioma, no entanto, a maioria dos pacientes ainda enfrenta o desafio de recorrência e progressão tumoral. Por esse motivo, medicamentos que podem melhorar ou recuperar a sensibilidade à quimioterapia podem contribuir para melhores resultados dos pacientes ${ }^{5}$. Para Guerreiro et $a l^{20}$ a radioterapia permite um bom controle tumoral estando associada em diversos estudos a uma sobrevida global de 5 anos na ordem de $80 \%$. As técnicas mais recentes de radioterapia procuram limitar ao máximo a exposição dos tecidos saudáveis à ação nociva da radiação e a braquiterapia estereotáxica parece não ter efeitos adversos a longo prazo, mas há necessidade de mais estudos sobre os efeitos que têm no SNC de uma criança 10, 15 ou 20 anos após a irradiação para que se possa afirmar a sua maior segurança neste grupo de pacientes. Buckner et al. ${ }^{28}$ demonstraram que o tratamento com procarbazina, lomustina e vincristina após a radioterapia no momento do diagnóstico inicial resultou em maior sobrevida livre de progressão, mas não sobrevida global, do que a radioterapia isolada. Já Choucar ${ }^{21}$ concluiu que a terapia de combinação imediata, radioterapia mais quimioterapia resultou em um ganho de 10,4 anos versus 4 anos em relação ao uso da radioterapia isolada. O paciente do caso relatado tratou com radioterapia pós-cirúrgica, porém não fez uso de tratamento quimioterápico.

Louis et al. ${ }^{11}$ relataram que os tumores de Grau I são benignos e na sua maioria curáveis com ressecção cirúrgica completa. Esses tumores ocorrem principalmente em crianças, diferentemente dos de Grau II ao IV, que são vistos em adultos. Já Claus et al. ${ }^{14}$ descreveram que o glioma de baixo grau é uma doença uniformemente fatal em adultos jovens (idade média de 41 anos), com média de sobrevida de aproximadamente 7 anos. Embora os pacientes com glioma de baixo grau tenham melhor sobrevida do que os pacientes com glioma de alto grau (Grau III ou IV), todos os gliomas de baixo grau eventualmente progridem para glioma e morte de alto grau. Guerreiro et al. ${ }^{20}$ relataram que os gliomas de baixo grau em idade pediátrica estão associados a uma baixa mortalidade e têm um risco de malignização muito reduzido, significando isto que muitas crianças afetadas atingem a vida adulta. Isso implica uma maior preocupação com a toxicidade e a alteração da qualidade de vida que os tratamentos atuais causam, que é o caso da radioterapia e quimioterapia. O paciente do presente relato quando iniciou o tratamento, apresentava 22 anos de idade, atualmente está respondendo bem ao tratamento realizado e encontra-se assintomático. Entretanto não podemos avaliar com prescisão a sobrevida desse caso, pois temos apenas dois anos de evolução.

Cardoso et al. ${ }^{24}$ verificaram as condições bucais dos pacientes submetidos a cirurgia associada à radioterapia ou a radioterapia exclusiva, com o objetivo de visualizar as lesões do complexo maxilomandibular resultantes dos procedimentos cirúrgico e radioterápico e encontraram a seguintes condições: a dermatite ocorreu em todos os pacientes, tendo sido observada a partir da segunda semana do início da radioterapia; a xerostomia esteve presente em todos os pacientes durante todo o período do tratamento; 
cinco dos doze pacientes apresentaram candidíase clínica; as alterações do paladar ocorreram em todos os pacientes em diferentes graus; a disfagia foi relatada por onze dos doze pacientes acompanhados, sendo que somente em dois houve gravidade que exigiu a colocação de sonda nasogástrica. Não foi observada a presença de cáries e nem presença de trismo. A osteorradionecrose também não foi vista, pois os principais fatores predisponentes foram bem controlados. No período durante a radioterapia os pacientes apresentaram queda no estado geral, porém com o término do tratamento foi verificado melhora considerável no estado geral dos pacientes. No estudo transversal de Quispe et al. ${ }^{27}$ não houve diferença estatística significativa na prevalência de cárie dentária entre o grupo estudo e o grupo controle, porém a doença periodontal foi mais prevalente no grupo estudo, com 90,7\%, diante de $60 \%$ do grupo controle. Os tecidos periodontais podem sofrer mudanças após o tratamento, podendo acontecer recessão gengival, perda de inserção gengival e elevado índice de placa bacteriana. O paciente relatado apresentou dermatite da pele irradiada. Como implicações bucais não foram observadas cárie de radiação, doença periodontal e osteorradionecrose. O paciente negou xerostomia, disfagia, candidíase, alteração no paladar e trismo.

\section{CONCLUSÃO}

O paciente relatado apresentou reações cutâneas na região irradiada, com descamação da pele, leve perda de cabelos e alguns episódios de cefaléia. Contudo não apresentou nenhuma complicação bucal decorrente da radioterapia, como xerostomia, disfagia, candidíase, alteração no paladar, trismo, cárie de radiação, doença periodontal e osteorradionecrose.

As novas técnicas de radiação parecem reduzir os efeitos adversos na exposição dos tecidos saudáveis. Entretanto há necessidade de mais estudos sobre seus efeitos em 10, 15 ou 20 anos após a irradiação, para assegurar a sua diminuição.

As orientações oferecidas pelos cirurgiões dentistas aos pacientes com neoplasias de cabeça e pescoço sobre cuidado com a saúde bucal antes, durante e depois do tratamento radioterápico podem evitar complicações decorrentes da radioterapia, permitindo identificação e tratamento odontológico precoce. Sendo então imprescindível para melhora da qualidade de vida dos pacientes. 


\section{REFERÊNCIAS BIBLIOGRÁFICAS}

Gomes FCA, Tortelli VP, Diniz L. Glia: dos velhos conceitos às novas funções de hoje e as que ainda virão. Estudos avançados 2013, v27 n77. [acesso em 15 de março de 2019]. Disponível em: http://www.scielo.br/pdf/ea/v27n77/v27n77a06.pdf

Dolecek TA, Propp JM, Stroup NE, Kruchko C. CBTRUS Statistical Report: Primary Brain and Central Nervous System Tumors Diagnosed in the United States in 2005-2009. Neuro-Oncology. 2012; 14 (1):1$49 \mathrm{v} 49$.

Sarmiento JM, Venteicher AS, Patil CG. Early versus delayed postoperative radiotherapy for treatment of low-grade gliomas. Cochrane Database of Systematic Reviews 2015, Issue 6. Art. No.: CD009229. DOI: 10.1002/14651858.CD009229.pub2.

Silva MC, Aguiar PHP. Gliomas e qualidade de vida. Jornal Brasileiro de Neurocirurgia. 2006, 17, 2, p. 61-66.

Gomes C, Carvalho DUB, Lima FC, Guedes VR. Gliomas IDH-Mutados: Revisão sobre diagnóstico, prognóstico e tratamento. Revista de Patologia do Tocantins 2017; 4(4): 44-47.

INSTITUTO NACIONAL DE CÂNCER (Brasil). Estimativa 2016. Incidência de Câncer no Brasil. Rio de Janeiro, 2015. [acesso em 16 de janeiro de 2019]. Disponível em: https://www.inca.gov.br/bvscontrolecancer/publicacoes/edicao/Estimativa_2016.pdf

Martins AR. Terapêutica dos Gliomas de Baixo Grau em Idade Pediátrica. 2017. 34f. Dissertação de Mestrado - Faculdade de Medicina Lisboa, Universidade de Lisboa, Lisboa.

Ransom BR, Kettenmann H. Electrical coupling, without dye coupling, between mammalian astrocytes and oligodendrocytes in cell culture Glia. 1990; 3(4):258-66.

Wang FYF, Li XJ. Angiogenesis in glioma. Vol 1, Issue 2, March-April 2018. http://www.jglioma.com on Friday, April 19, 2019, IP: 10.232.74.23

Cohen A, Holmen S, Colman H. IDH1 and IDH2 Mutations in Gliomas. Current neurology and neuroscience reports. 2013; 13(5):345. doi: 10.1007/s11910-013-0345-4.

Louis DN, Ohgaki H, Wiestler OD, Cavenee WK, Burger PC, Jouvet A, Scheithauer BW, Kleihues P. The 2007 WHO classification of tumors of the central nervous system. Review Acta Neuropathol. 2007, 114(2):97-109.

Malheiros SMF, Stávale JN, Franco CMR, Brago FM, Gabbai AA. Astrocitomas Difusos de Baixo Grau de Malignidade. Revista Neurociências. 1998; 6: 75-80.

Egan KM, Nabors LB, Olson JJ, Monteiro AN, Browning JE, Madden MH. Rare TP53 genetic variant associated with glioma risk and outcome. J Med Genet. 2012; 49:420-421.

Claus EB, Walsh KM, Wiencke JK, Molinaro AM, Wiemels JL, Schildkraut JM, Bondy ML, Berger M, Jenkins R, Wrensch M. Survival and low grade glioma: the emergence of genetic information. Neurosurg Focus. 2015 January; 38(1): E6. doi:10.3171/2014.10.FOCUS12367. 
Louis DN, Perry A, Reifenberger G, VonDeimling A, Figarella-Branger D, Cavenee WK, Ellison DW. (2016). The 2016 World Health Organization Classification of Tumors of the Central Nervous System: a summary. Acta Neuropathologica, 131(6), 803-820. https://doi.org/10.1007/s00401-016-1545-1

Pirzkall A, Nelson SJ, McKnight TR, Takahashi MM, Li X, Graves EE, Verhey LJ, Wara WW, Larson DA, Sneed PK. Metabolic imaging of low-grade gliomas with three dimensional magnetic resonance spectroscopy. Int J Radiat Oncol Biol Phys 2002;53:1254-1264.

Duffau H, Capelle L. Preferential brain locations of lowgrade gliomas. Comparison with glioblastomas and review of hypothesis. Cancer 2004; 100(12):2622-6.

Silva MC, Miotto EC, Lucia MCS, Aguiar PHP. Investigação neuropsicológica pré-operatória em pacientes com glioma de baixo grau. J Bras Neurocirurg. 2007, 18 (3): 35-39.

Chang EF, Potts MB, Keles GE, Lamborn KR, Chang SM, Barbaro NM. Seizure characteristics and control following resection in 332 patients with low-grade gliomas. Journal of Neurosurgery. 2008; 108(2):22735.

Guerreiro-Stucklin AS, Tabori U, Grotzer MA. The Changing Landscape of Pediatric Low-Grade Gliomas: Clinical Challenges and Emerging Therapies. Neuropediatrics. 2016, 47(2), 70-83. https://doi.org/10.1055/s-0035-1570491

Choucair AK. Low grade glioma: a journey towards a cure. Chin Clin Oncol 2017; 6(4):43. http://dx.doi.org/10.21037/cco.2017.07.08

Chaichana KL, Cabrera-Aldana EE, Jusue-Torres I, Wijesekera O, Olivi A, Rahman M, QuinonesHinojosa A. When gross total resection of a glioblastoma is possible, how much resection should be achieved? World Neurosurgery, 2014; 82(1-2): e257-e265.

Ramina R, Coelho Neto M, Fernandes YB, Borges G, Honorato DC, Arruda WO. Astrocitomas tectais de baixo grau: o tratamento cirúrgico é uma alternativa? Análise de oito casos com longa evolução. Arq. Neuro-Psiquiatr. 2005; 63(1):40-45.

Cardoso MFA, Novikoff S, Tresso A, Segreto RA, Cervantes O. Prevenção e controle das sequelas bucais em pacientes irradiados por tumores de cabeça e pescoço. Radiol Bras. 2005; 38(2): 107-115.

Corrêa CF. Radioterapia intersticial para o tratamento dos tumores encefálicos. Arq Bras Neurocir, 2002; 21(1-2): 8-40.

Coelho Neto M. Radiosurgery for Brain Gliomas. J Bras Neurocirurg. 2014; 25 (3): 261- 264.

Quispe RA, Cremonesi AL, Gonçalves JK, Rubira CM, da Silva Santos PS. Estudo caso-controle de índices de doenças bucais em indivíduos com câncer de cabeça e pescoço após terapia antineoplásica. Einstein (São Paulo). 2018;16(3):eAO4245. https://doi.org/10.1590/S1679-45082018AO4245

Buckner JC et al. Radiation plus Procarbazine, CCNU, and Vincristine in Low-Grade Glioma. N Engl J Med 2016; 374;14. 